\title{
Interspecific Crosses and Backcrosses between Diploid Vaccinium darrowii and Tetraploid Southern Highbush Blueberry
}

\author{
Dario J. Chavez and Paul M. Lyrene ${ }^{1}$ \\ Department of Horticultural Sciences, University of Florida, Gainesville, FL 32611 \\ AdDitional INDEX words. Vaccinium corymbosum, darrow's evergreen blueberry, 2n gametes, breeding, polyploidy
}

\begin{abstract}
Diploid Vaccinium darrowii Camp has been used in breeding tetraploid southern highbush blueberry (Vaccinium corymbosum L.) as a source of reduced chilling requirement, adaptation to hot, wet summers, and resistance to leaf diseases. $V$. darrowii in Florida is quite variable, but most crosses have involved only one $V$. darrowii clone, Fla. 4B. The use in breeding of a wider range of $V$. darrowii accessions would provide beneficial diversity in the blueberry cultivated gene pool. The purpose of this research was to determine the functional $2 \mathrm{n}$ gamete frequency of numerous $V$. darrowii genotypes when crossed with tetraploid $V$. corymbosum, and to study the pollen fertility and backcross ability of the interspecific $(V$.darrowii $\times V$. corymbosum) hybrids to $V$. corymbosum. Crosses between diploid $V$. darrowii and tetraploid highbush blueberry cultivars had low fruit set compared with the $V$. darrowii $\times$ V. darrowii and highbush $\times$ highbush crosses. The unusually high number of hybrids per pollinated flower (HPF) in certain $4 x-2 x$ or $2 \mathrm{x}-4 \mathrm{x}$ crosses was attributed to high functional $2 \mathrm{n}$ gamete production in certain $V$. darrowii genotypes. Diploid Vaccinium fuscatum Aiton and diploid $V$. darrowii $\times V$. fuscatum hybrids, when crossed with southern highbush blueberry cultivars, were equally productive of hybrids whether used as male or female parents. Variation in frequency of functional 2n gametes in $V$. darrowii, expressed as high HPF, was present within plants (megaspores vs. microspores) and among $V$. darrowii plants. Of the 114 interspecific $(V$. darrowii $\times V$. corymbosum) hybrids studied, 106 had pollen stainability $>50 \%$. This indicated that most of these hybrids were tetraploid, because triploid blueberries, like most triploid plants, are highly sterile. Twenty-two $V$. darrowii $\times V$. corymbosum hybrids were backcrossed to tetraploid highbush blueberry cultivars. Fruit set was variable, but large populations of vigorous hybrids were obtained. Lower fruit set was associated with hybrids that had lower pollen fertility. It should be possible to obtain plants of cultivar quality in a few generations of backcrosses.
\end{abstract}

Vaccinium L. section Cyanococcus $\mathrm{L}$. includes diploid $(2 \mathrm{n}=$ $2 \mathrm{x}=24)$, tetraploid $(2 \mathrm{n}=4 \mathrm{x}=48)$, and hexaploid $(2 \mathrm{n}=6 \mathrm{x}=72)$ species native to North America (Camp, 1945; Vander Kloet, 1983 , 1988). The main cultivated groups are lowbush blueberry (Vaccinium angustifolium Aiton), highbush blueberry (Vaccinium corymbosum and their hybrids), and rabbiteye blueberry (Vaccinium virgatum Aiton). Since the establishment of blueberry breeding programs, genes from various wild blueberry relatives have been introgressed into the cultivated gene pool. In the blueberry breeding program at the University of Florida, Vaccinium myrsinites Lam. (4x), Vaccinium darrowii $(2 \mathrm{x})$, and $V$. virgatum (6x), were successfully used as parents to reduce the chilling requirement of northern highbush blueberries (Goldy and Lyrene 1984; Moore, 1965; Sharpe, 1953; Sharpe and Darrow, 1959).

Hybridization between tetraploid northern highbush blueberry cultivars and diploid $V$. darrowii was first reported by Sharpe and Darrow (1959). V. darrowii clones Fla. 4A and Fla. 4B were used in these foundation crosses (Sharpe and Sherman, 1971). From 1600 pollinations, 31 fertile hybrids were obtained (Sharpe and Darrow, 1959). The 2 n gametes in $V$. darrowii and a strong triploid block in Vaccinium allowed tetraploid hybrids to be obtained from these crosses (Cockerham and Galleta, 1976; Den Nijs and Peloquin, 1977; Goldy and Lyrene, 1984; Johnston et al., 1980; Lyrene and Sherman, 1983; Marks, 1966;

Received for publication 21 Jan. 2009. Accepted for publication 2 Mar. 2009. We thank Dr. Jose X. Chaparro and Dr. Eileen A. Kabelka for their suggestions and commentaries for the completion of this manuscript.

${ }^{1}$ Corresponding author. E-mail: lyrene@ufl.edu.
Moore, 1965; Ortiz et al., 1992a, 1992b; Sharpe and Darrow, 1959; Woodell and Valentine, 1961).

Undesired characteristics from $V$. darrowii (i.e., short, twiggy plant structure, small fruit, and long fruit development period) were eliminated by crossing and selection. Acceptable fruit and plant quality were obtained. Phenotypically, the $F_{1}$ interspecific hybrids were intermediate between the parents, and when the hybrids were backcrossed to tetraploid southern highbush blueberry cultivars, seedlings with variable morphology and high fertility were obtained (Lyrene, 1997). All selections from the southern highbush blueberry program at Gainesville, FL, have $V$. darrowii in their pedigree (Sharpe and Sherman, 1971).

Obtaining fertile tetraploid hybrids by crossing $V$. darrowii with tetraploid highbush blueberry depends on $2 \mathrm{n}$ gamete production in $V$. darrowii, which is infrequent and confined to certain $V$. darrowii genotypes. Several methods have been used to determine the $2 \mathrm{n}$ gamete frequency of diploid species. Stelly and Peloquin (1983) estimated the frequency of $2 \mathrm{n}$ gamete production in various diploid Solanum L. plants by microscopic examination of pollen sporads ( $2 \mathrm{n}$ pollen) and whole-ovule preparations (cell nuclei size and $2 \mathrm{n}$ eggs), and by crossing diploid and tetraploid species. No correlation was found between the results of microscopic examination and the results of the crosses. Megalos and Ballington (1988) made crosses between diploid and tetraploid blueberry species. They found that diploid Vaccinium elliottii Chapm. clones that produced numerous tetraploid seedlings when crossed with one tetraploid highbush blueberry did not necessarily produce numerous tetraploid hybrids when crossed with a different 
tetraploid plant. Bretagnolle and Thompson (1995) counted 4x seeds or seedlings after $2 \mathrm{x}-4 \mathrm{x}$ and $4 \mathrm{x}-2 \mathrm{x}$ crosses to assess $2 \mathrm{n}$ pollen and/or $2 \mathrm{n}$ egg production in individual diploid plants of potato and other genera. The purpose of our research was to study the functional $2 \mathrm{n}$ gamete frequency in plants of $V$. darrowii present in Florida when crossed with tetraploid $V$. corymbosum by determining the number of hybrids produced per cross, their level of fertility, and their ability to cross with tetraploid southern highbush blueberry and other Vaccinium species.

\section{Materials and Methods}

\section{Plant material}

Hybridization studies. Diploid $V$. darrowii clones, diploid $V$. darrowii $\times V$. fuscatum hybrids, and tetraploid southern highbush blueberry ( $V$. corymbosum) cultivars were used in hybridization. $V$. darrowii clones selected in the Florida panhandle and in the central Florida peninsula and $V$. darrowii $\times$ $V$. fuscatum hybrids selected from a moist wood in the peninsula near Davenport, FL, were propagated by softwood cuttings. The selected plants were vigorous and healthy and had highly glaucous foliage. The $V$. darrowii panhandle clones (Lyrene, 1986) were from Cotton Landing, Sumatra, Wilma, and Chattahoochee, FL, all in or near the Apalachicola National Forest. The $V$. darrowii clones from the Florida peninsula (Lyrene, 1986) were selected from Davenport, near Haines City, and from Highlands County, FL. Softwood cuttings of the $V$. darrowii and $V$. darrowii $\times V$. fuscatum hybrids were rooted in trays of sphagnum peat and perlite $(1: 1)$. Rooted cuttings were transplanted into $4-\mathrm{L}$ nursery containers containing sphagnum peat and perlite $(1: 1)$ and were maintained in a greenhouse in Gainesville, FL. $V$. darrowii and $V$. darrowii $\times$ $V$. fuscatum hybrids are evergreen, and have no chilling requirement.

Tetraploid southern highbush blueberry ( $V$. corymbosum hybrids) cultivars or advanced selections were selected from the University of Florida blueberry breeding program's field nursery. The plants were dug from the field in Dec. 2006, were transplanted into 8-L nursery containers filled with sphagnum peat and perlite, and were chilled for more than $1000 \mathrm{~h}$ in a walk-in cooler at $5^{\circ} \mathrm{C}$ with no light. After being chilled, the southern highbush blueberry plants were placed inside a beeproof greenhouse.

Pollen stainability. Plant material used to assess pollen fertility included two $V$. darrowii $\times V$. corymbosum hybrids from crosses made in 2004, three from crosses made in 2005, and 109 from crosses made in 2006. Plants were grown in Citra, FL, in a high-density nursery. These plants were selected from the University of Florida blueberry germplasm collection because they were the only seedlings from these crosses whose vegetative morphology clearly showed they were hybrids. Plants were transplanted to 4-L nursery containers and placed in a cooler at $5{ }^{\circ} \mathrm{C}$ with no light on 20 Dec. 2007. In late Jan. 2008 , they were moved to a bee-proof greenhouse in Gainesville, FL.

BaCkCrossing EXPeriments. Plants used in crosses with southern highbush blueberry cultivars $(4 \mathrm{x})$ included two $V$. darrowii $\times V$. corymbosum hybrids from crosses made in 2004, three interspecific hybrids from crosses made in 2005, and 17 interspecific hybrids from crosses made in 2006. The plants were collected from field nurseries at University of Florida
Plant Science Unit in Citra, FL, transplanted to 8-L nursery containers of sphagnum peat, and placed in a cooler at $5{ }^{\circ} \mathrm{C}$ with no light in December. The interspecific plants from crosses in 2006 were not given additional chilling beyond what they received in the field. In late January, the selected interspecific plants were placed in a bee-proof greenhouse in Gainesville, FL.

Plant material used in reciprocal crosses with $V$. virgatum (6x) included two $V$. darrowii $\times V$. corymbosum hybrids with low pollen fertility from crosses made in 2004 and 2005, and one interspecific hybrid with high pollen fertility from crosses made in 2005. The interspecific hybrids were transplanted from the field and placed in a cooler at $5^{\circ} \mathrm{C}$ with no light on $20 \mathrm{Dec}$. 2006. In late Jan. 2007, they were placed in a bee-proof greenhouse as described before.

Plant material used in crosses with $V$. darrowii $(2 \mathrm{x})$ included two of the $V$. darrowii $\times V$. corymbosum hybrids that had high pollen fertility, FL07-111-F 1 and FL07-112-F 1 , derived from crosses made in 2005. The interspecific hybrids were moved from a greenhouse in Gainesville, FL, and were placed in a cooler at $5^{\circ} \mathrm{C}$ with no light in Dec. 2007. The $V$. darrowii clones were selected from the germplasm collection available at the University of Florida in Gainesville. They were evergreen and were not chilled. In late Jan. 2008, the selected interspecific hybrids and the $V$. darrowii clones were placed in a bee-proof greenhouse.

\section{Hybridization studies}

Open flowers from the plants selected as females were removed to avoid unplanned pollination. Female plant-to-plant variation was eliminated as a confounding factor by dividing individual plants into two parts to compare intraspecific crosses ( $V$. darrowi $\times V$. darrowii and $V$. corymbosum $\times V$. corymbosum) with interspecific crosses $[V$. darrowii $\times V$. corymbosum and reciprocal, and $(V$. darrowii $\times V$. fuscatum $)$ hybrids $\times V$. corymbosum and reciprocal] (Morrow, 1943). On each plant, one side was randomly assigned to an interspecific cross and the other to an intraspecific cross. Flowers were emasculated before pollination by removing the corolla and anthers with forceps. Pollination was performed by touching the stigma with pollen that had been collected a few minutes earlier on the thumbnail. For $V$. darrowii $\times V$. darrowii crosses, $\approx 250$ flowers were pollinated per plant, and 150 flowers were pollinated per plant for highbush $\times$ highbush crosses. For interspecific crosses, $\approx 500$ flowers were pollinated per plant.

Berries were harvested when fully ripe. The first 20 berries that ripened were opened individually to determine seed content. Seeds from additional berries were extracted using a food blender, after which they were dried at room temperature on a desk top and stored in coin envelopes at $5{ }^{\circ} \mathrm{C}$ for 3 months.

\section{Determination of functional 2 n gamete frequency}

Seeds from each cross were counted and classified into two categories: plump or shriveled. The number of plump seeds per pollinated flower was calculated for each cross. In Nov. 2007, seed packages of crosses made in 2007 were treated with a fungicide (captan at $0.1 \mathrm{~g}$ per package) and planted on the top layer of 4-L nursery containers of sphagnum peat. The nursery containers were maintained in a greenhouse with intermittent mist for 2 to 3 months, until most seeds had germinated. The number of seedlings per pollinated flower for each cross was calculated. 
In Feb. 2008, when the seedlings from the interspecific crosses were 1 to $2 \mathrm{~cm}$ high, they were transferred to trays of sphagnum peat, 100 seedlings each. In May 2008, when the seedlings were 4 to $8 \mathrm{~cm}$ high, they were planted in a highdensity nursery in Citra, FL, with plant-to-plant spacing of $10 \mathrm{~cm}$ and row-to-row spacing of $40 \mathrm{~cm}$. The high-density nursery was maintained with overhead irrigation and fertilization when required. After $60 \mathrm{~d}$ in the high-density nursery, the seedlings were counted and classified into two categories: hybrids or selfs based on visual comparisons of morphology or resemblance to the female parent (Figs. 1-3). The strong triploid block in Vaccinium and the relatively low frequency of $2 \mathrm{n}$ gametes required that a very large numbers of flowers be pollinated (Cockerham and Galleta, 1976; Goldy and Lyrene, 1984; Marks, 1966; Moore, 1965; Lyrene and Sherman, 1983; Ortiz et al., 1992a, 1992b; Sharpe and Darrow, 1959; Woodell and Valentine, 1961). With so many flowers pollinated, low levels of selfing may have occurred and the morphology of seedlings was examined to confirm that they were in fact interspecific hybrids.

\section{Pollen stainability of $\boldsymbol{V}$. darrowii $\times \boldsymbol{V}$. corymbosum hybrids}

Open flowers were collected to determine pollen stainability in January and Feb. 2008. Flowers were dried and pollen was stained with $1 \%$ aceto-carmine solution $(1 \mathrm{~g}$ of carmine boiled in $45 \mathrm{~mL}$ of glacial acetic acid $+55 \mathrm{~mL}$ of $\mathrm{H}_{2} \mathrm{O}$ ). Microphotographs were taken using a Moticam 1000 1.3-megapixel microscope digital camera with the Motic Images Plus Version 2.0ML software (Motic Instruments, Richmond, British Columbia, Canada) mounted on a phase-contrast microscope (Leitz, Wetzlar, Germany). About 80 random pollen grains were examined for each plant, and the percentage of stained grains was determined.

Sterile pollen grains in water or aceto-carmine appeared shriveled, unstained, or abnormal in shape, and had varying degrees of pollen inflation (Dermen, 1940). Abnormal pollen grains may result from chromosome pairing abnormalities during meiosis (Goldy and Lyrene, 1984; Lyrene and Sherman, 1983).

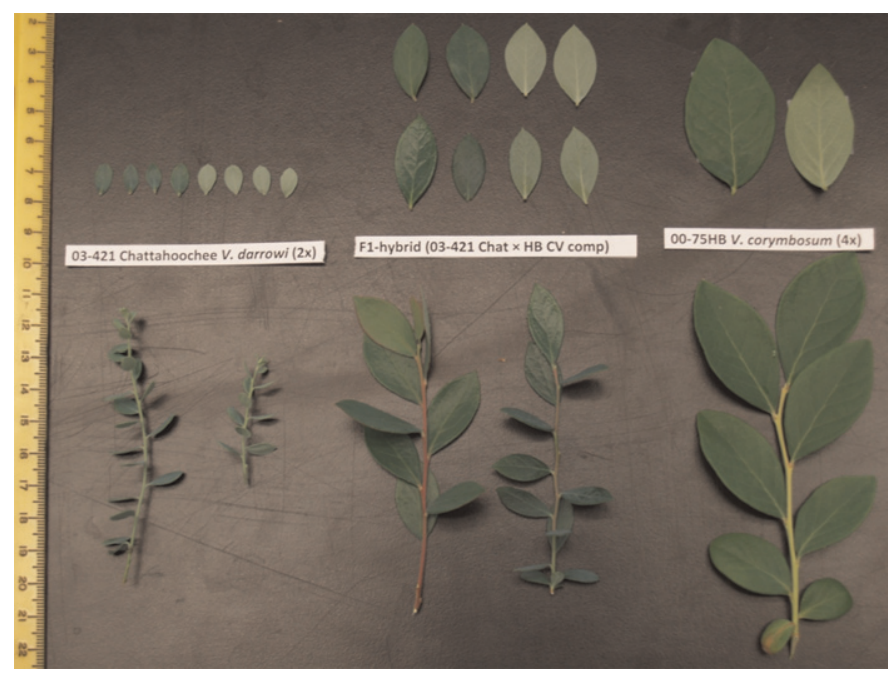

Fig. 1. Comparative differences in leaf morphology between diploid Vaccinium darrowii (left), interspecific $(V$. darrowii $\times$ Vaccinium corymbosum) hybrids (center), and tetraploid $V$. corymbosum (right). Leaves were taken from 2year-old plants.

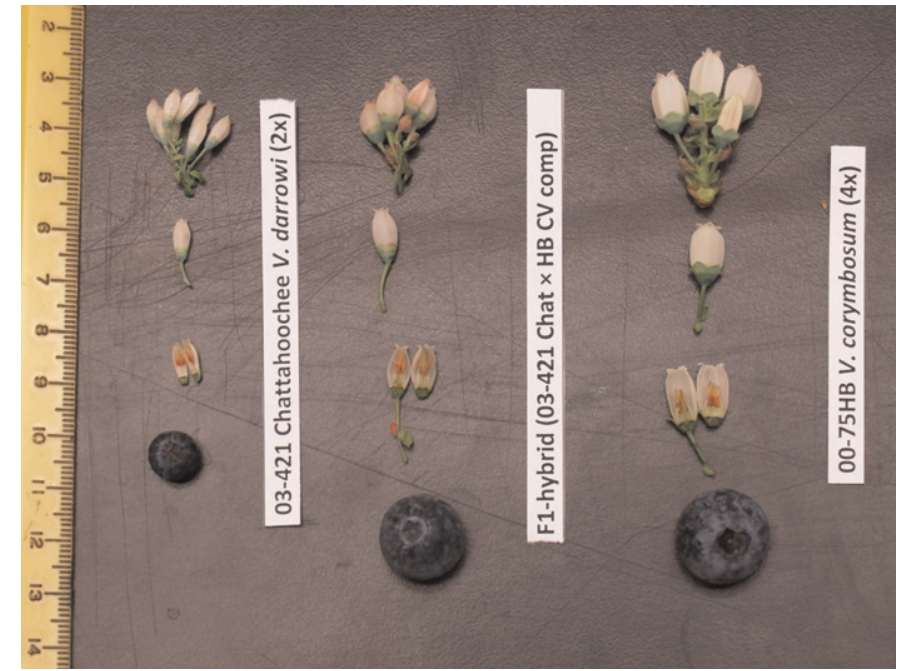

Fig. 2. Comparative differences in flower and fruit morphology for diploid Vaccinium darrowii (left), interspecific $(V$. darrowii $\times$ Vaccinium corymbosum) hybrids (center), and tetraploid $V$. corymbosum (right). Flowers and fruits were taken from 2-year-old plants.

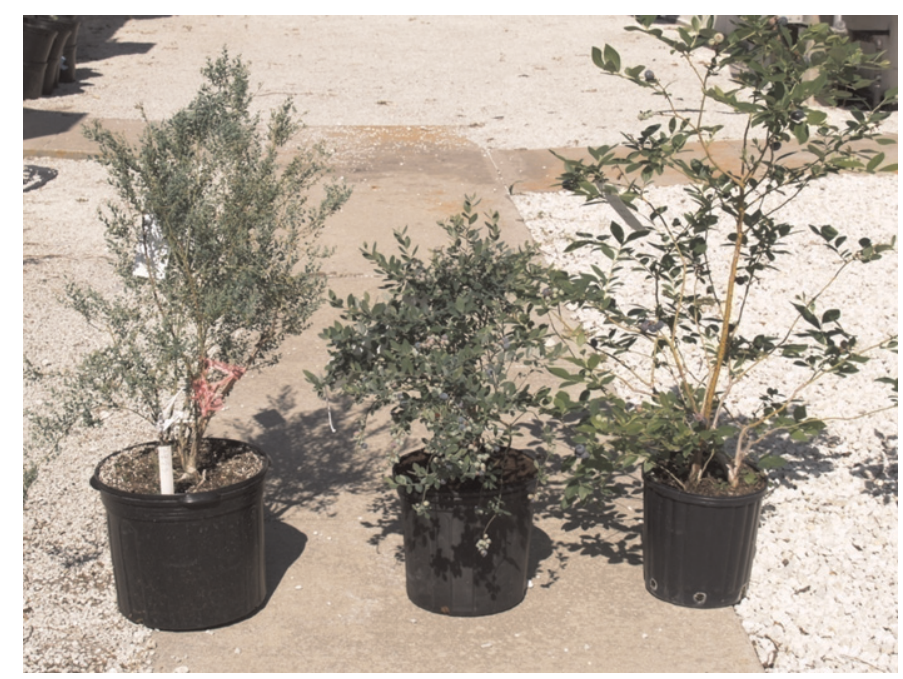

Fig. 3. Comparative differences in plant architecture of diploid Vaccinium darrowii (left), interspecific $(V$. darrowii $\times$ Vaccinium corymbosum $)$ hybrid (center), and tetraploid $V$. corymbosum (right). The plastic container (not including the plant) on the left is $30 \mathrm{~cm}$ tall. Plants are 2 years old.

\section{Backcrossing experiments}

INTERSPECIFIC $(V$. DARROWII $\times V$. CORYMBOSUM $)$ HYBRIDS $\times$ SOUTHERN HIGHBUSH BLUEBERRY. The selected interspecific plants were placed in a bee-proof greenhouse for use as parents in crosses with tetraploid southern highbush blueberry cultivars or advanced selections. The interspecific hybrids were used as female parents with southern highbush blueberry cultivars, except for one from crosses made in 2005 that was also used as male parent. Emasculation and pollination were done as described above. The interspecific hybrids from crosses made in 2004 and 2005 were divided into two sections. One section was pollinated with pollen from tetraploid southern highbush blueberry cultivars. The other section was pollinated with pollen from hexaploid $V$. virgatum 'Florida Rose' (Clark and Finn, 2006). About 250 flowers were pollinated per section for each plant in Feb. 2007. The interspecific hybrids from crosses 
made in 2006 were not divided into sections. Between 30 and 500 flowers on each plant were pollinated in Feb. 2008. Fruit harvest, seed extraction, seed planting, and seedling identification were as described in the hybridization studies.

INTERSPECIFIC HYBRIDS $\times \boldsymbol{V}$. VIRGATUM AND RECIPROCALS. TWO $V$. darrowii $\times V$. corymbosum hybrids that had low pollen fertility were crossed as male and female parents with hexaploid $V$. virgatum cv. Florida Rose. The idea was that the lowfertility $V$. darrowii $\times V$. corymbosum hybrids might be triploid, and might produce $2 \mathrm{n}$ gametes that, when fused with normal gametes from hexaploid $V$. virgatum, would produce hexaploid hybrids. One $V$. darrowii $\times V$. corymbosum hybrid with high pollen fertility, from crosses made in 2005, was also used as male and female parent in crosses with 'Florida Rose'. About 250 flowers were pollinated per section for each plant. Fruit harvest, seed extraction, seed planting, and seedling identification were as described above.

INTERSPECIFIC HYBRIDS $\times \boldsymbol{V}$. DARROWII AND RECIPROCALS. Vaccinium darrowii $\times V$. corymbosum hybrids FL07-111- $\mathrm{F}_{1}$ and FL07-112-F 1 , which had high pollen fertility, were selected as male and female parents for backcross to diploid $V$. darrowii. The two $V$. darrowii clones used as male and female parents in these crosses were known from earlier crosses to be high $2 \mathrm{n}$ egg producers. The goal was to obtain tetraploid plants with $75 \%$ of their genes derived from $V$. darrowii. About 500 flowers were pollinated for each cross. Fruit harvest and seed extraction were as described above.

\section{Data analysis}

Data collected for each cross included fruit set percentage, number of plump seeds per pollinated flower (PPF), number of seedlings per pollinated flower (SPF), and number of hybrids per pollinated flower (HPF). Means for PPF, SPF, and HPF for different treatments were separated using least squares means by Tukey's test, with a significance level of 5\%. Means for fruit set percentage were separated using chi-square "test of independence," with a significance level of 5\%. In these chi-square tests, each pollinated flower was considered an observation with two possible responses: set or nonset. The null hypothesis of the chi-square "test of independence" was that the ratio of set to nonset was the same for the two crosses being compared. Data analysis and analysis of variance (ANOVA) were performed using the PROC GLM, and PROC FREQ procedures of SAS (version 9.1; SAS Institute, Cary, NC).

\section{Results and Discussion}

\section{Hybridization studies}

Several diploid $V$. darrowii clones produced a high frequency of functional $2 \mathrm{n}$ gametes when crossed to tetraploid southern highbush blueberry cultivars. No association was found between functional $2 \mathrm{n}$ pollen and $2 \mathrm{n}$ egg production for $V$. darrowii clones - that is, clones that frequently produced $2 n$ pollen were not those that frequently produced $2 n$ eggs. Variation in frequency of functional $2 \mathrm{n}$ gamete production in diploid $V$. darrowii was present within plants (megaspores vs. microspores) and among plants within $V$. darrowii races. $V$. darrowii clones that produced numerous fertile hybrids when used as males in $4 \mathrm{x}-2 \mathrm{x}$ crosses did not necessarily produce many hybrids when used as females in $2 x-4 x$ crosses, and vice versa. Exceptional clones allowed us to produce many hybrids from $4 \mathrm{x}-2 \mathrm{x}$ and $2 \mathrm{x}-4 \mathrm{x}$ crosses.
Number of seedlings per pollinated flower and HPF for $V$. darrowii $(2 \mathrm{x}) \times V$. corymbosum $(4 \mathrm{x})$ and reciprocals varied widely among crosses. Previous $V$. darrowii $(2 \mathrm{x}) \times V$. corymbosum (4x) crosses [in 2001 and 2005 (P.M. Lyrene, unpublished data)] produced numerous seedless berries, and most of the seedlings obtained were not hybrids. From 4739 pollinations of $V$. darrowii clones from Lake Istokpoga (Istokpoga race), only three interspecific hybrids were obtained [0.001 HPF (data not shown)]. This compares with 133 hybrids obtained from 7340 pollinations when $V$. darrowii clones from the Ocala National Forest (Ocala race) were used [0.021 HPF (data not shown)]. No cross in 2001 or 2005 produced more than 0.100 HPF. Fruit set ranged from $0 \%$ to $93.4 \%$ in the interspecific crosses made in 2006 (P.M. Lyrene, unpublished data). One $V$. darrowii clone from the Florida panhandle race (FL03-421-P) crossed with a composite of pollen from highbush blueberry cultivars gave unusually high values for PPF, SPF, and HPF (140 interspecific hybrids were obtained by pollinating 1406 flowers) compared with the eight other crosses made in 2006 (three interspecific hybrids from 2498 pollinated flowers for all other crosses combined). The higher production of hybrids was attributed to high functional $2 \mathrm{n}$ egg production by FL03-421-P.

Three $V$. darrowii clones, FL03-421-P, FL03-422-P, and FL06-660-I, averaged higher in PPF, SPF, and HPF than the other seven $V$. darrowii clones used as females in $V$. darrowii $\times$ $V$. corymbosum crosses in $2007(P<0.05)$ (Table 1$)$. No association between higher fruit set and higher HPF was found in 2007. This was due to high levels of parthenocarpic berry production in some $V$. darrowii clones. Crosses made in 2007 confirmed the results of 2006. FL03-421-P produced a high functional $2 \mathrm{n}$ egg frequency when crossed with southern highbush blueberry cultivars. Although pollinations were a laborious method of screening for functional $2 \mathrm{n}$ gamete production, they provided repeatable results.

Fruit set ranged from $0.9 \%$ to $44.0 \%$ (Table 1) in $V$. corymbosum $(4 \mathrm{x}) \times V$. darrowii $(2 \mathrm{x})$ crosses made in 2007 . Low fruit set was expected in these crosses because of the difference in ploidy levels between the parents. Three interspecific crosses, FL06-446-HB $\times$ FL03-419-I, FL07-92-HB $\times$ FL03-418-I, and FL-95-50-HB $\times$ FL03-423-P, gave surprisingly high PPF, SPF, and HPF compared with the mean of the seven other $V$. corymbosum $(4 \mathrm{x}) \times V$. darrowii $(2 \mathrm{x})$ crosses made in $2007(P<0.0001)$. Unusually high levels of functional 2 n gamete production in the diploid $V$. darrowii parents are the most likely reason for the high success rate in these crosses. Fruit set from intraspecific crosses averaged $78.1 \%$ for $V$. corymbosum and $74.3 \%$ for $V$. darrowii (Table 2) in 2007.

Overall Comparisons. Six diploid $V$. darrowii clones were used as pollen and seed parents in crosses with tetraploid highbush blueberry cultivars in 2007 (Table 3 ). One $V$. darrowii clone (FL03-421-P) produced far more hybrid seedlings when used as seed parent. Three others (FL03-419-I, FL03-418-I, and FL03-423-P) gave more hybrids when used as pollen parents. Vaccinium darrowii FL03-421-P gave 40.8 hybrids per 100 pollinated flowers when used as seed parent, but only 5.9 when used as pollen parent $(P<0.0001)$. FL03-419-I gave only 4.5 hybrids per 100 pollinated flower when used as a seed parent compared with 34.2 when used as pollen parent. Two other $V$. darrowii clones, FL03-418-I and FL03-423-P, also produced far more hybrids when used as pollen parents $[P<0.0001$ in each case (Table 3$)]$. When $V$. darrowii clones were compared, a clone's success as a pollen parent was not 
Table 1. Number of flowers pollinated, and fruit, seed, and hybrid seedling production in interspecific crosses between Vaccinium darrowii and southern highbush blueberry (Vaccinium corymbosum) cultivars and reciprocals.

\begin{tabular}{|c|c|c|c|c|c|c|c|c|}
\hline Female & & Male & Flowers (no.) & Berries (no.) & Fruit set $(\%)$ & PPF (no.) $)^{x}$ & SPF (no.) $)^{x}$ & $\mathrm{HPF}_{(\text {no. })^{\mathrm{x}}}$ \\
\hline V. darrowii & $x$ & Highbush & & & & & & \\
\hline FL03-414-I ${ }^{z}$ & $x$ & FL03-228-HB & 540 & 94 & 17.4 & 0.44 & 0.078 & 0.022 \\
\hline FL03-404-I & $x$ & FL03-286-HB & 667 & 112 & 16.8 & 0.35 & 0.024 & 0.000 \\
\hline FL03-419-I & $\times$ & FL92-84-HB & 644 & 237 & 36.8 & 1.97 & 0.087 & 0.045 \\
\hline FL03-418-I & $\times$ & FL01-297-HB & 554 & 38 & 6.9 & 0.11 & 0.023 & 0.000 \\
\hline FL03-422-P & $\times$ & FL88-53-HB & 541 & 225 & 41.6 & 1.80 & 0.153 & 0.125 \\
\hline FL06-660-I & $\times$ & Southern Belle-HB & 551 & 302 & 54.8 & 6.23 & 0.161 & 0.152 \\
\hline FL03-402-I & $x$ & FL07-49-HB & 551 & 7 & 1.3 & 0.19 & 0.087 & 0.000 \\
\hline Highbush & $x$ & $V$. darrowii & & & & & & \\
\hline FL06-446-HB & $\times$ & FL03-419-I & 569 & 138 & 24.3 & 2.33 & 0.342 & 0.342 \\
\hline FL02-16-HB & $x$ & FL03-421-P & 596 & 29 & 4.9 & 0.15 & 0.059 & 0.059 \\
\hline FL95-50-HB & $\times$ & FL03-423-P & 549 & 155 & 28.2 & 0.35 & 0.093 & 0.093 \\
\hline FL01-277-HB & $x$ & FL06-702-P & 505 & 27 & 5.4 & 0.10 & 0.081 & 0.079 \\
\hline Southern Belle-HB & $x$ & FL03-414-I & 533 & 28 & 5.3 & 0.14 & 0.043 & 0.043 \\
\hline FL00-45-HB & $x$ & FL06-719-I & 359 & 158 & 44.0 & 0.25 & 0.042 & 0.042 \\
\hline
\end{tabular}

${ }^{\mathrm{z}}$ Diploid $V$. darrowii, $-\mathrm{P}=$ Florida panhandle race, $-\mathrm{I}=$ Istokpoga race.

y_HB $=$ tetraploid $V$. corymbosum.

${ }^{x} \mathrm{PPF}=$ plump seeds per pollinated flower, $\mathrm{SPF}=$ seedlings per pollinated flower, HPF $=$ hybrids per pollinated flower.

Table 2. Results of crossing diploid and tetraploid Florida Vaccinium species in section Cyanococcus measured by fruit set (\%), number of plump seeds per pollinated flower (PPF), seedlings per pollinated flower (SPF), and hybrids per pollinated flower (HPF).

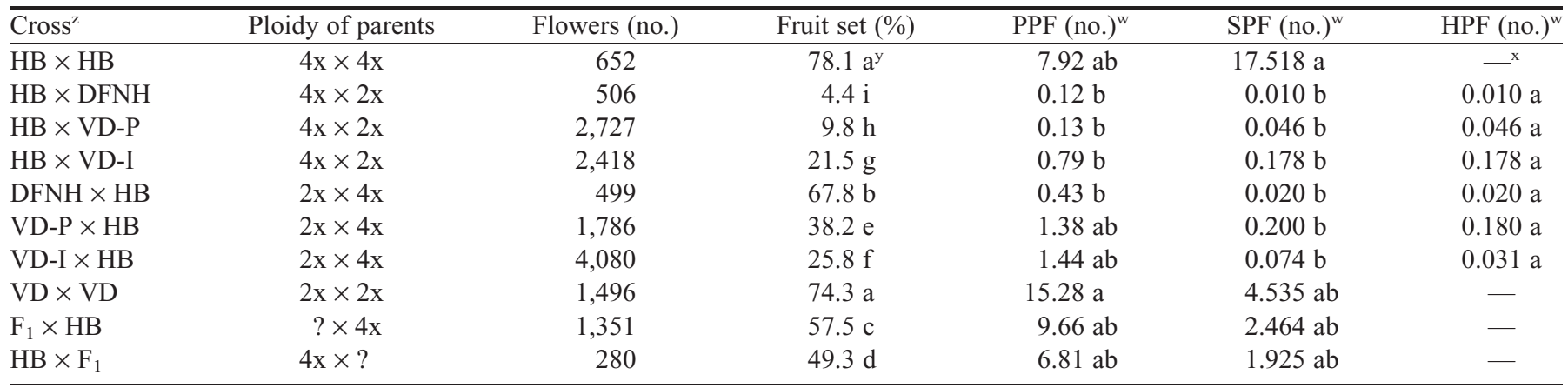

${ }^{\mathrm{z}} \mathrm{HB}=$ Vaccinium corymbosum, DFNH $=$ natural hybrid $($ Vaccinium darrowii $\times$ Vaccinium fuscatum $)$, VD-P $=V$. darrowii Florida panhandle race, $\mathrm{VD}-\mathrm{I}=V$. darrowii Istokpoga race, $\mathrm{F}_{1}=$ interspecific hybrid $(V$. darrowii $\times V$. corymbosum $)$.

${ }^{y}$ Similar letters within a column indicate means not significantly different. Tukey's test for PPF, SPF, and HPF at $\alpha=0.05$; chi-square "test of independence" for fruit set at $\alpha=0.05$.

$\mathrm{x} \_$_ no data. Because the parents are fully cross-compatible, almost all the seedlings from controlled crosses are expected to be hybrids.

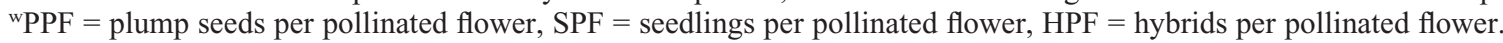

related to its success as a seed parent. Because most of the hybrids produced from our crossing experiments have been fertile (and presumably tetraploid), hybrid production rate from these crosses indicated the rate of functional $2 \mathrm{n}$ gamete production in the $V$. darrowii parent. Megalos and Ballington (1988) reported similar results. They found that the frequency of 2 gametes varied among Vaccinium species and among clones within species. They also found that the frequency of $2 n$ gametes production differed for megaspores and microspores in the same plant.

Two diploid natural hybrids of $V$. darrowii $\times V$. fuscatum, collected from a moist forest in the central Florida peninsula, were used in reciprocal crosses with tetraploid highbush blueberry cultivars. Fruit set percentage was 15 times higher when the natural hybrids were used as the seed parent compared with the reciprocals, but the berries had very few seeds $(P<$ 0.05) (Table 2). Lyrene (P.M. Lyrene, unpublished data) obtained no hybrid seedlings after pollinating $\approx 1000$ flowers of tetraploid cultivars with pollen from two diploid $V$. fuscatum plants from eastern Alachua County, FL. Overall, diploid $V$. darrowii, diploid $V$. fuscatum, and diploid interspecific ( $V$. darrowii $\times V$. fuscatum, natural hybrids), when crossed with southern highbush blueberry cultivars, were equally productive of hybrids whether used as male or female parents. 
Table 3. Results of reciprocal interspecific crosses between Vaccinium darrowii and southern highbush blueberry (Vaccinium corymbosum) cultivars. ${ }^{\mathrm{z}}$ The goal was to see whether it was better to use $V$. darrowii as the seed parent or the pollen parent. $V$. darrowii clone names end in $-\mathrm{I}$ or $-\mathrm{P}$ and tetraploid highbush blueberry names end in HB.

\begin{tabular}{|c|c|c|c|c|c|c|c|c|}
\hline$\overline{\text { Female }^{y}}$ & & Male & Flowers (no.) & Berries (no.) & Fruit set $(\%)$ & $\mathrm{P}: 100 \mathrm{~F}^{\mathrm{x}}$ (no.) & $\mathrm{S}: 100 \mathrm{~F}^{\mathrm{x}}$ (no.) & $\mathrm{H}: 100 \mathrm{~F}^{\mathrm{x}}$ (no.) \\
\hline FL03-414-I & $x$ & FL03-228-HB & 540 & 94 & 17.4 & 44.9 & 7.8 & 2.2 \\
\hline & & & & $P$ value & $<0.0001$ & $<0.0001$ & 0.3281 & 0.4021 \\
\hline \multirow[t]{2}{*}{ FL07-108-HB } & $x$ & FL03-404-I & 557 & 5 & 0.9 & 3.4 & 1.1 & 1.1 \\
\hline & & & & $P$ value & $<0.0001$ & $<0.0001$ & 0.5974 & 0.2513 \\
\hline FL03-421-P & $x$ & FL00-59-HB & 544 & 220 & 40.4 & 124.2 & 42.6 & 40.8 \\
\hline & & & & $P$ value & $<0.0001$ & $<0.0001$ & $<0.0001$ & $<0.0001$ \\
\hline FL03-419-I & $x$ & FL92-84-HB & 644 & 237 & 36.8 & 196.7 & 8.7 & 4.5 \\
\hline \multirow[t]{2}{*}{ FL06-446-HB } & $x$ & FL03-419-I & 569 & 138 & 24.3 & 233.3 & 34.2 & 34.2 \\
\hline & & & & $P$ value & $<0.0001$ & 0.0088 & $<0.0001$ & $<0.0001$ \\
\hline FL03-418-I & $x$ & FL01-297-HB & 554 & 38 & 6.9 & 10.6 & 2.3 & 0.0 \\
\hline FL07-92-HB & $x$ & FL03-418-I & 400 & 133 & 33.3 & 121.9 & 46.0 & 46.0 \\
\hline \multicolumn{9}{|l|}{ Totals: } \\
\hline VD & $x$ & $\mathrm{HB}$ & $3,650^{\mathrm{w}}$ & 930 & $25.2^{\mathrm{u}}$ & 86.7 & 11.0 & 7.9 \\
\hline \multirow[t]{2}{*}{ HB } & $x$ & VD & 3,204 & 488 & 16.1 & 70.5 & 16.8 & 16.8 \\
\hline & & & & $P$ value & $<0.0001^{\mathrm{v}}$ & 0.6370 & 0.1490 & 0.0345 \\
\hline
\end{tabular}

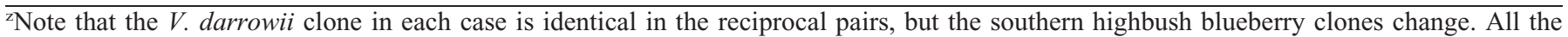
southern highbush blueberry clones used are highly fertile.

${ }^{y}$ Diploid $V$. darrowii (VD), $-\mathrm{P}=$ Florida panhandle race, $-\mathrm{I}=$ Istokpoga race; tetraploid $V$. corymbosum (HB) represented by $-\mathrm{HB}$.

${ }^{x} \mathrm{P}: 100 \mathrm{~F}=$ plump seeds per 100 pollinated flower, $\mathrm{S}: 100 \mathrm{~F}=$ seedlings per 100 pollinated flower, $\mathrm{H}: 100 \mathrm{~F}=$ hybrids per 100 pollinated flower.

${ }^{\text {w}}$ Total values per cross type.

"Chi-square "test of independence" at $P \leq 0.01$. Comparisons were made within columns and between reciprocal crosses.

"Mean averages per cross type.

As expected, the crosses between species of the same ploidy level made in 2007, $V$. darrowii $\times V$. darrowii and $V$. corymbosum $\times V$. corymbosum, had higher fruit set $(74.3 \%$ and $78.1 \%$, respectively) than the tetraploid $\times$ diploid crosses $(P<0.05$, Table 2). The homoploid crosses had higher PPF and SPF than the $4 \mathrm{x}-2 \mathrm{x}$ or the $2 \mathrm{x}-4 \mathrm{x}$ crosses. Although the means differed substantially, they were not significantly different at $P=0.05$ due to the low number of replicates.

\section{Pollen stainability of $\boldsymbol{V}$. darrowii $\times \boldsymbol{V}$. corymbosum hybrids}

Vaccinium darrowii $\times V$. corymbosum hybrid pollen stainability was highly variable among clones. Of the five interspecific hybrids produced in crosses made in 2004 and 2005, FL06-105- $\mathrm{F}_{1}$ and FL07-110- $\mathrm{F}_{1}$ had low pollen stainability (14.5\% and $21.4 \%$, respectively), and FL06-107- $\mathrm{F}_{1}$, FL07$111-\mathrm{F}_{1}$, and FL07-112- $\mathrm{F}_{1}$ had high pollen stainability $(99.4 \%$, $95.5 \%$, and $98.3 \%$, respectively). Crosses made in 2006 produced 109 hybrids whose average pollen stainability was $88.1 \%$. Pollen stainability less than $50 \%$ was found in $5.57 \%$ (six plants) of the 109 interspecific hybrids made in 2006 (Fig. 4). These plants had shriveled pollen with abnormal shapes that failed to stain with $1 \%$ aceto-carmine (Dermen, 1940). Pollen stainability was greater than $50 \%$ in 103 of the 109 hybrid plants $(94.9 \%)$. The interspecific hybrids with high pollen stainability were probably tetraploids, and interspecific hybrids with low pollen stainability may have been triploids or aneuploids (Cockerham and Galleta, 1976; Goldy and Lyrene,

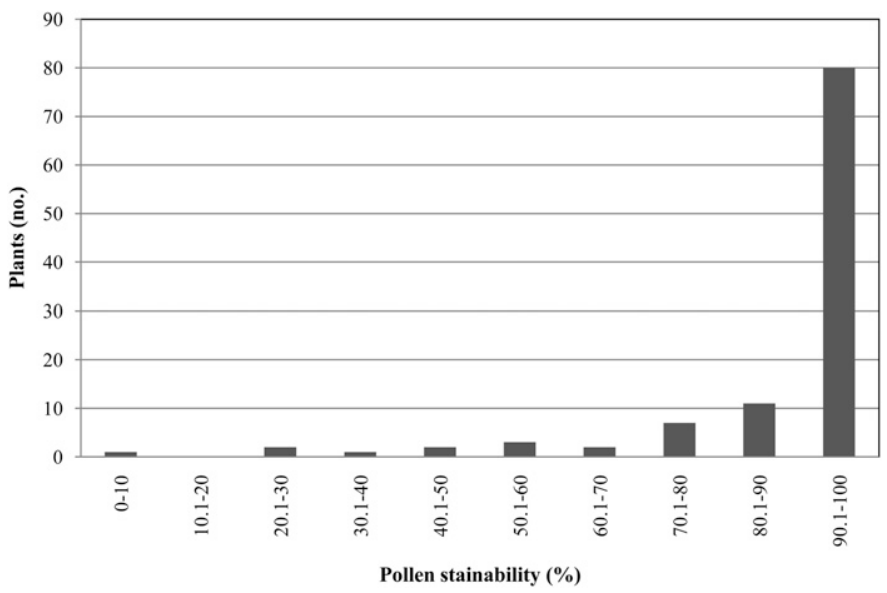

Fig. 4. Histogram showing the distribution of plants for percentage of pollen staining in a population of 109 interspecific (Vaccinium darrowii $\times$ Vaccinium corymbosum) hybrids.

1984; Lyrene and Sherman, 1983). The tetraploid interspecific hybrids should be easy to backcross to the tetraploid gene pool. The putative triploid interspecific hybrids could potentially be backcrossed to hexaploid $V$. virgatum through 2 gamete production. In this way, genes from $V$. darrowii and $V$. corymbosum could be moved to the $V$. virgatum gene pool (Ehlenfeldt and Vorsa, 1993). 
Hybrid FL07-110-F 1 ( . darrowii $\times V$. corymbosum $)$ produced numerous $2 \mathrm{n}$ microspores and unstained tetrads as seen under the microscope. Meiotic abnormalities during pollen formation probably produced the many abnormal tetrads (unstained sporads) and the $2 \mathrm{n}$ pollen sporads. FL07-110- $\mathrm{F}_{1}$ was probably triploid because of the reduced pollen fertility and the high 2n gamete production (Cockerham and Galleta, 1976; Goldy and Lyrene, 1984; Lyrene and Sherman, 1983). In a preliminary study, hybrid FL06-105- $\mathrm{F}_{1}$ was determined to be triploid $(2 \mathrm{n}=3 \mathrm{x}=36)$ by cytogenetic studies of pollen mother cells during metaphase I and prophase I (data not shown).

\section{Backcrossing experiments}

INTERSPECIFIC $(\boldsymbol{V}$. DARROWII $\times \boldsymbol{V}$. CORYMBOSUM $)$ HYBRIDS $\times$ SOUTHERN HIGHBUSH BLUEBERRY. The interspecific $(V$. darrowii $\times$ $V$. corymbosum) hybrids were backcrossed to southern highbush blueberry cultivars and selections. Fruit set for these crosses was variable. Lower fruit set was associated with interspecific hybrids with low pollen fertility, FL06-105- $\mathrm{F}_{1}$ and FL07-110-F $\mathrm{F}_{1}$. Fruit set for the backcrosses made in 2007 ranged from $3.2 \%$ to $97.8 \%$ (Table 4). Low fruit set, $3.2 \%$ and $36.3 \%$, occurred in crosses when the interspecific hybrids FL07-110-F $\mathrm{F}_{1}$ and FL06-105- $\mathrm{F}_{1}$ were the seed parents. These two interspecific hybrids had low pollen stainability. The other four backcrosses had fruit set from $49.3 \%$ to $97.8 \%$. The interspecific hybrids used in these backcrosses had high pollen stainability. PPF and SPF were associated with pollen stainability of the interspecific hybrids (Table 4).

Fruit set values for $V$. darrowii $\times V$. corymbosum hybrids pollinated with pollen from tetraploid highbush blueberry cultivars in 2008 ranged from $0.3 \%$ to $86.9 \%$. SPF for these crosses averaged 4.41, twice the SPF value for backcrosses made in 2007. Pollen stainability for the population of these interspecific hybrids was highly variable (Fig. 4). Of the 17 interspecific hybrids used in these backcrosses, three hybrids had low pollen stainability (data not shown). These results were similar to those in 2007 . The diploid $\times$ tetraploid crosses, $V$. darrowii $\times V$. corymbosum and reciprocals, as expected, had much lower fruit set and PPF than the homoploid crosses (Table 2 ). These results are consistent with the findings of the previous studies (Darrow et al., 1949; Meader and Darrow, 1944; Rousi, 1966; Sharpe, 1953; Sharpe and Darrow, 1959).

Berry weight was highly variable depending on the female parent. The largest berries were produced by highbush blueberry parents $(1.1-2.0 \mathrm{~g})$ and the smallest by $V$. darrowii $(0.3-0.4 \mathrm{~g})$. Berry weight of the interspecific hybrids was intermediate $($ mean $=1.0 \mathrm{~g})$ and probably too small for a commercial blueberry cultivar. The number of large seeds per berry was highest for highbush $\times$ highbush crosses (31.7 large seeds per berry), lowest for the interploid crosses (3.1-8.7 large seeds per berry), and intermediate for crosses between highbush blueberry and the interspecific hybrids (11.8-13.1 large seeds per berry). Seed production in highbush blueberry $\times$ interspecific hybrids and reciprocal was sufficient to produce large backcross populations.

INTERSPECIFIC HYBRIDS $\times V$. VIRGATUM AND RECIPROCALS. Crosses of the interspecific $(V$. darrowii $\times V$. corymbosum) hybrids $\times V$. virgatum gave few seeds. Even though the number of seedlings obtained was low, the interspecific hybrids with lower pollen stainability were successfully crossed with the hexaploid $V$. virgatum 'Florida Rose' (Table 4). Fruit set was

Table 4. Result of hybridization of Vaccinium darrowii $\times$ Vaccinium corymbosum hybrids with other Florida Vaccinium species, measured by fruit set (\%), and number of plump seeds (PPF) and seedlings per pollinated flower (SPF).

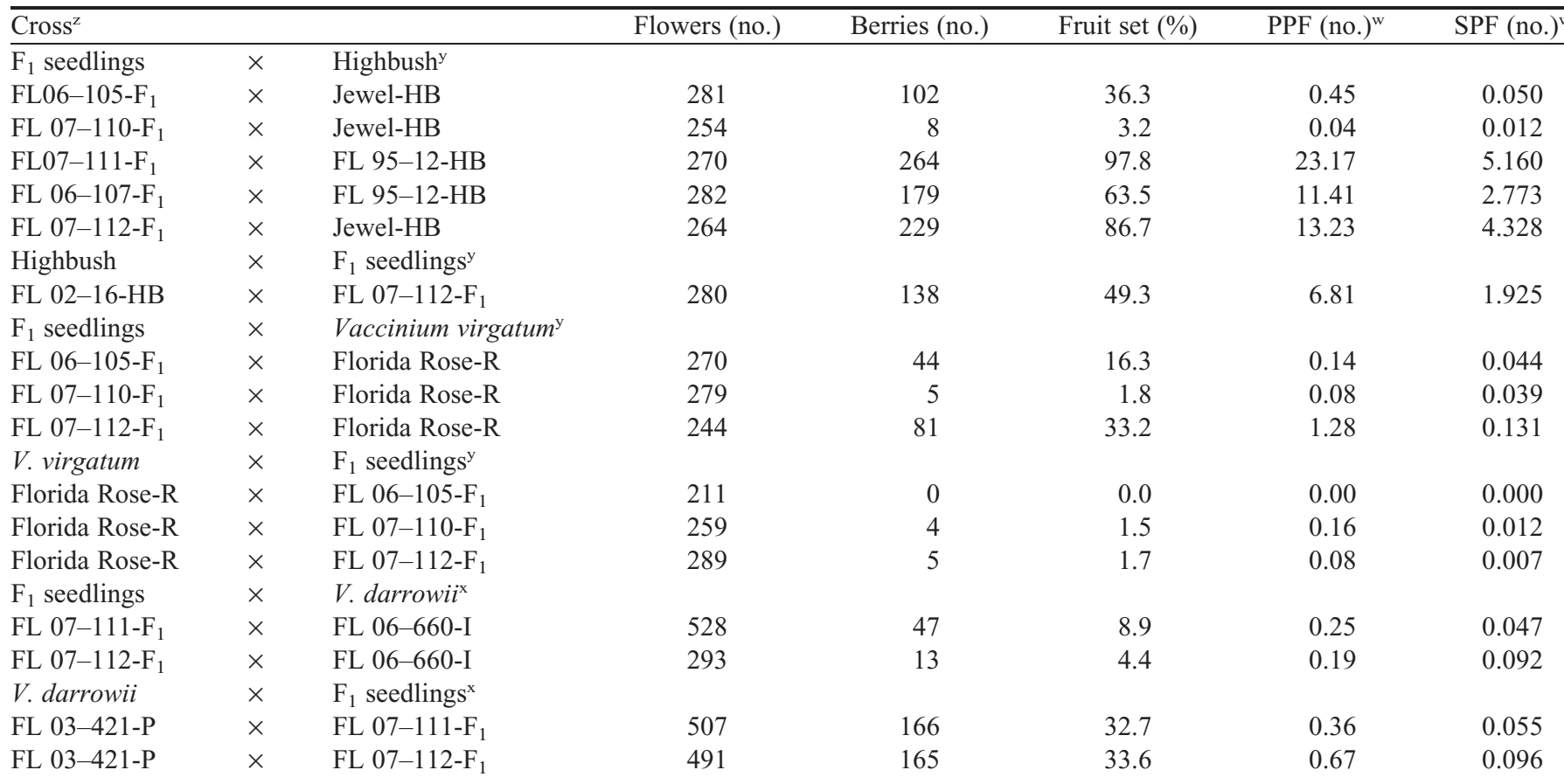

$\mathrm{z}_{-} \mathrm{F}_{1}=$ interspecific hybrid $[V$. darrowii $\times$ southern highbush blueberry $(V$. corymbosum $)$ cultivars], $-\mathrm{HB}=$ highbush blueberry cultivars. $\mathrm{R}=$ hexaploid $V$. virgatum $(\mathrm{syn}=$ Vaccinium ashei $) \mathrm{cv}$. Florida Rose, $\mathrm{I}=V$. darrowii Istkopoga race, $\mathrm{P}=V$. darrowii Florida panhandle race.

${ }^{\mathrm{y}}$ Crosses made in 2007.

${ }^{\mathrm{x}}$ Crosses made in 2008.

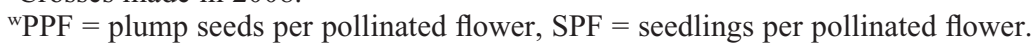


$16.3 \%$ for FL06-105- $\mathrm{F}_{1}$ and $1.8 \%$ for FL07-110- $\mathrm{F}_{1}$ when crossed as seed parents with $V$. virgatum. FL07-112- $\mathrm{F}_{1}$ fruit set was $33.2 \%$. PPF and SPF were proportional to fruit set. SPF was very low for all of these crosses, but highest for the cross with FL07-112- $\mathrm{F}_{1}$. It is not know whether these $V$. darrowii $\times$ highbush blueberry hybrids were triploid, tetraploid, or aneuploid. Some of these hybrids crossed with $V$. virgatum could produce hexaploid, pentaploid, or near pentaploid progeny (Ehlenfeldt and Vorsa, 1993; Lyrene, 1997). Most of the hybrid seedlings, after one growing season in the field, were highly vigorous and appeared to be valid hybrids, but their chromosome numbers have been not yet determined.

INTERSPECIFIC HYBRIDS $\times \boldsymbol{V}$. DARROWII AND RECIPROCALS. The preliminary results in 2008 indicate that backcrosses to $V$. darrowii can be successful. The $V$. darrowii $\times V$. corymbosum hybrids that had the highest pollen staining were just as successful as tetraploid highbush blueberry cultivars in backcrosses to diploid $V$. darrowii (Table 4).

Fruit set for interspecific ( $V$. darrowii $\times V$. corymbosum) hybrids $\times V$. darrowii and reciprocal was lower when the interspecific hybrids were used as seed parents. Increased fruit set for $V$. darrowii $\times$ interspecific hybrids may have been due to 2 n egg production by $V$. darrowii or might indicate a higher level of parthenocarpy (Table 4). PPF and SPF have not been a good estimate of the number of hybrid seedlings obtained, and until the seedlings are examined during flowering, we will not know how many tetraploid hybrids have been produced from the backcrosses.

Mean berry weight was highly variable depending on the female parent. The number of large seeds per berry was high (mean $=13.1$ large seeds per berry) in the tetraploid homoploid crosses between $\mathrm{F}_{1}(V$. darrowii $\times V$. corymbosum $)$ hybrids and $V$. corymbosum and low in the tetraploid $\times$ diploid crosses between $\mathrm{F}_{1}$ hybrids and $V$. darrowii $(2 \mathrm{x})$ and reciprocals (3.2 and 2.6 large seeds per berry, respectively). Vaccinium corymbosum $(4 \mathrm{x}) \times V$. darrowii $(2 \mathrm{x})$ and reciprocal crosses produced an average of 3.1 and 8.7 large seeds per berry, respectively (data not shown).

\section{Summary}

Backcrossing $V$. darrowii $\times V$. corymbosum hybrids to several Vaccinium species (including the cultivated gene pool) produced large populations of hybrids. These should make it possible to obtain plants of cultivar quality in a few generations of backcrosses with desired traits from wild species. The interspecific hybrids with high pollen fertility were easily backcrossed to southern highbush blueberry cultivars. (Cockerham and Galleta, 1976; Goldy and Lyrene, 1984; Lyrene and Sherman, 1983; Sharpe and Darrow, 1959).

\section{Literature Cited}

Bretagnolle, F. and J.D. Thompson. 1995. Tansley review no. 78. Gametes with the somatic chromosome number: Mechanism of their formation and role in the evolution of autopolyploid plants. New Phytol. 129:1-22.

Camp, W.H. 1945. The North American blueberries with notes on other groups of Vacciniaceae. Brittonia 5:203-275.
Clark, J.R. and C.E. Finn (eds.). 2006. Register of new fruit and nut varieties. List 43. HortScience 41:1101-1133.

Cockerham, L.E. and G.J. Galleta. 1976. A survey of pollen characteristics in certain Vaccinium species. J. Amer. Soc. Hort. Sci. 101:671-676.

Darrow, G.M., H. Dermen, and D.H. Scott. 1949. A tetraploid blueberry from a cross of diploid and hexaploid species. J. Hered. 40:304-306.

Den Nijs, T.P.M. and S.J. Peloquin. 1977. 2n gametes in potato species and their function in sexual polyploidization. Euphytica 26:585-600.

Dermen, H. 1940. Colchicine polyploidy and technique. Bot. Rev. 6:599-635.

Ehlenfeldt, M.K. and N. Vorsa. 1993. The generation, evaluation and utilization of hexaploid progeny from $3 \mathrm{x} \times 3 \mathrm{x}$ crosses of highbush blueberry: Germplasm transfer and $2 \mathrm{n}$ gametes in blueberry. Acta Hort. 346:95-102.

Goldy, R.G. and P.M. Lyrene. 1984. Meiotic abnormalities of Vaccinium ashei $\times V$. darrowi hybrids. Can. J. Genet. Cytol. 26:146-151.

Johnston, S.A., T.P.M. Den Nijs, S.J. Peloquin, and R.E. Hanneman. 1980. The significance of genic balance to endosperm development in interspecific crosses. Theor. Appl. Genet. 57:5-9.

Lyrene, P.M. 1986. Variation within Vaccinium darrowi blueberry in Florida. HortScience 21:512-514.

Lyrene, P.M. 1997. Value of various taxa in breeding tetraploid blueberries in Florida. Euphytica 94:15-22.

Lyrene, P.M. and W.B. Sherman. 1983. Mitotic instability and 2n gamete production in Vaccinium corymbosum $\times$ V. elliottii hybrids. J. Amer. Soc. Hort. Sci. 108:339-342.

Marks, G.E. 1966. The enigma of triploid potatoes. Euphytica 15:285290.

Meader, E.M. and G.M. Darrow. 1944. Pollination of the rabbiteye blueberry and related species. Amer. Soc. Hort. Sci. 45:267-274.

Megalos, B.S. and J.R. Ballington. 1988. Unreduced pollen frequencies versus hybrid production in diploid-tetraploid Vaccinium crosses. Euphytica 39:271-278.

Moore, J.N. 1965. Improving highbush blueberries by breeding and selection. Euphytica 14:39-48.

Morrow, E.B. 1943. Some effects of cross-pollination experiments versus self-pollination in cultivated blueberries. Proc. Amer. Soc. Hort. Sci. 42:469-472.

Ortiz, R., L.P. Bruederle, T. Laverty, and N. Vorsa. 1992a. The origin of polyploids via $2 \mathrm{n}$ gametes in Vaccinium section Cyanococcus. Euphytica 61:241-246.

Ortiz, R., N. Vorsa, L.P. Bruederle, and T. Laverty. 1992b. Occurrence of unreduced pollen in diploid blueberry species, Vaccinium sect. Cyanococcus. Theor. Appl. Genet. 85:55-60.

Rousi, A. 1966. The use of north-European Vaccinium species in blueberry breeding. Acta Agriculture Scandinavica Suppl. 16:50-54.

Sharpe, R.H. 1953. Horticultural development of Florida blueberries. Proc. Florida State Hort. Soc. 66:188-190.

Sharpe, R.H. and G.M. Darrow. 1959. Breeding blueberries for the Florida climate. Proc. Florida State Hort. Soc. 71:308-311.

Sharpe, R.H. and W.B. Sherman. 1971. Breeding blueberries for lowchilling requirement. HortScience 6:145-147.

Stelly, D.M. and S.J. Peloquin. 1983. Methods to detect 2n female gametophytes in Solanums. Amer. Potato J. 60:821.

Vander Kloet, S.P. 1983. The taxonomy of Vaccinium Cyanococcus: A summation. Can. J. Bot. 61:256-266.

Vander Kloet, S.P. 1988. The genus Vaccinium in North America. Pub. 1828. Research Branch, Agriculture Canada, Ottawa.

Woodell, S.R.J. and D.H. Valentine. 1961. Studies in British primulas. IX. Seed incompatibility in diploid-autotetraploid crosses. New Phytol. 60:282-294. 